\title{
Structural, Morphological and Spectroelectrochemical Characterization of Poly (2-ethyl aniline)
}

\author{
Andreia L. Schemid ${ }^{a}$, Susana I. Córdoba de Torresi ${ }^{a^{*}}$, Alessandra N. Bassetto ${ }^{b}$ and Ivani A. Carlos ${ }^{c}$ \\ anstituto de Química, Universidade de São Paulo, CP 26077, 05513-970, São Paulo - SP, Brazil \\ binstituto de Química de São Carlos, Universidade de São Paulo, CP 780, 13560-970, São Carlos - SP, Brazil \\ ${ }^{\mathrm{c}}$ Departamento de Química, Universidade Federal de São Carlos, CP 676, 13565-905, São Carlos - SP, Brazil
}

\begin{abstract}
Neste trabalho foi feito um estudo comparativo da estrutura, morfologia e resposta espectroeletroquímica da poli (2-etilanilina) e da polianilina em função do contra-íon. Os ácidos minerais conferem uma estrutura mais esponjosa a filmes de poli (2-etilanilina) enquanto que ácidos orgânicos tornam a estrutura homogênea e compacta. Para a poli (2-etilanilina) a resposta eletroquímica depende muito da relação carga/tamanho do eletrólito utilizado, devido a efeitos estéricos e eletrônicos. As relações entre as bandas de absorção e os pares redox mostram que mudanças na absorbância são proporcionais a corrente faradaica que é observada nos voltamogramas.
\end{abstract}

In this paper a comparative study of the structure, morphology, and the spectroelectrochemical response of poly (2-ethyl aniline) and polyaniline for different counterions is presented. Spongeous structure of poly (2-ethyl aniline) is obtained when mineral acids are used, while homogeneous and compact films are formed using organic acids. The electrochemical response of poly (2-ethyl aniline) depends on the charge/size ratio of the counterion due to both steric and electronic effects. The correlation between the absorption bands and the redox couple show that the changes in absorbance are proportional to the faradaic current observed in the voltammograms.

Keywords: polyaniline, poly(2-ethylaniline), spectroelectrochemistry, DSC, SEM.

\section{Introduction}

Conducting organic polymers have shown great potential for many applications, including rechargeable batteries, corrosion protection, light emitting diodes, molecular sensors, electrochromic devices and gas separation membranes $^{1-6}$. For these applications, the polymers must be highly processable and chemically stable for long periods of time. Polyaniline (PANI) has been one of the most widely studied conducting polymers because of its chemical and oxidative stability. However, as it is common with other conjugated polymers, polyaniline is limited by poor thermal processability and solvent solubility ${ }^{7}$.

Improved solubility can be achieved by introducing bulky alkyl substituents into the polyaniline backbone, but limitations are then imposed on the conductivity of the polymer produced. The conductivity of polyaniline and

*e-mail: storresi@quim.iq.usp.br

Presented at the XI Simpósio Brasileiro de Eletroquímica e Eletroanalítica, Maragogi - AL, Brazil, April 5-9, 1999. Guest editor: Luis Alberto Avaca. the solubility of substituted polyanilines can be achieved by copolymerization. A deep knowledge of the electrochemical properties and the study and characterization of the homopolymers is a very important path to find the route to synthesize copolymers with tailored properties.

Polymeric films present many complicated mechanistic aspects due to electronic transfer through the film specially to sites which are far from the polymer/substrate interface. The movement of polymeric chains to allow the accommodation of different species like ions and solvent molecules inside the film, is very important. The form of the voltammograms strongly depends on counterion, solvent, thickness, etc., so a wide variety of E/i profiles have been found ${ }^{8}$.

Kaufman et al. ${ }^{9}$ have proposed a model for charge transportation through polymeric films in the sense that propagation of charge takes place by auto exchange electronic reactions among oxidized and reduced species positioned at neighboring sites in the film. This model has been also suggested for PANI films in a recent paper ${ }^{10}$ dealing with the optical behavior of poly(2-ethyl aniline) films. It has been shown that a large substituent like ethyl and the chemical 
nature of the counterion are very important parameters in determining the energy of the electronic bands of PANI films. The presence of the substituent significantly perturbs the geometry of the chains, leading to a hypsochromic shift of the polaronic absorption band. It has been shown, that depending on the size of the counterion, the presence of an alkyl group in the ortho position influences the participation of this anion in the ionic exchange process due to steric hindrance. The electron-donating effect of the ethyl substituent is completely disregarded in comparison to the steric effect that produces an increase of the torsion angle between phenyl rings. The electronic effect is important in the second oxidation process and it is evidenced by the diminution of the redox potential of the emeraldine/ pernigraniline couple.

In this paper, a comparative structural and morphological study of poly(2-ethyl aniline) and polyaniline is presented. Besides, in order to reach a better understanding of the electrochromic phenomena of these materials, monochromatic absorption curves were obtained at different wavelengths, simultaneously with voltammetric recordings. By differentiating the absorption curves, it was possible to relate each electrochemical process with their absorption bands. This analysis is specially useful in the case of poly(2ethylaniline) which shows very complicated i/E profiles. This method has already been applied for nickel hydrox$\operatorname{ide}^{11}$ and poly $(o \text {-metoxyaniline })^{12}$ and it is based on the fact that changes in absorbance during electrochemical processes are proportional to the electric charge consumed in those processes when the differential absorption curves coincide with the voltammetric profiles. In this way, both curves must coincide at the wavelengths in which the species taking part in the electrochemical reaction absorb light. This analysis is correct if all the electric charge consumed during the electrochromic process is faradaic. So, in the case of complicated voltammetric profiles, this method allows to separate electrochemical processes occurring very close in potential, as it is the case of substituted polyanilines.

\section{Experimental}

Poly(2-ethylaniline) (2-ethyl PANI) films were prepared onto transparent glass $/ \mathrm{SnO}_{2}$ conducting substrates (resistivity $16 \Omega / \square$ ), from a $1 \mathrm{~mol} \mathrm{~L}^{-1} \mathrm{HCl}+0.5 \mathrm{~mol} \mathrm{~L}^{-1} 2$ ethylaniline solution by applying triangular potential sweeps $\left(0.05 \mathrm{Vs}^{-1}\right)$ in the -0.2 and $0.85 \mathrm{~V}$ potential range. For comparison, polyaniline (PANI) films were grown onto the same substrates from a $1 \mathrm{~mol} \mathrm{~L}^{-1} \mathrm{HCl}+0.5 \mathrm{~mol} \mathrm{~L}-1$ aniline solution by applying triangular potential sweeps $\left(0.05 \mathrm{Vs}^{-1}\right)$ in the 0.2 and $0.7 \mathrm{~V}$ (SCE) potential range. After deposition, films were rinsed with purified water and placed into an one- compartment cell with two optical windows. The electrolytes were $0.8 \mathrm{~mol} \mathrm{~L}^{-1} \mathrm{HCl}, \mathrm{HClO}_{4}$, p-toluene sulfonic acid (PTSA) or camphor sulfonic acid (HCSA) solutions. A platinum wire was used as counter electrode and all potentials are referred to the saturated calomel electrode (SCE).

Spectroelectrochemical experiments were performed under potentiodynamic conditions with an EG\&G PAR Model 362 potentiostat/galvanostat by placing the electrochemical cell in the optical pathway of a modified Micronal spectrophotometer. Temperature was $25^{\circ} \mathrm{C}$ and all solutions were prepared from analytical grade chemicals and water ultra purified by the Elga UHQ system. Aniline and 2-ethylaniline were distilled under reduced pressure in order to assure the exclusivity of the monomeric form, HCSA was recrystallized for using in spectroelectrochemical experiments and all other chemicals were used as received.

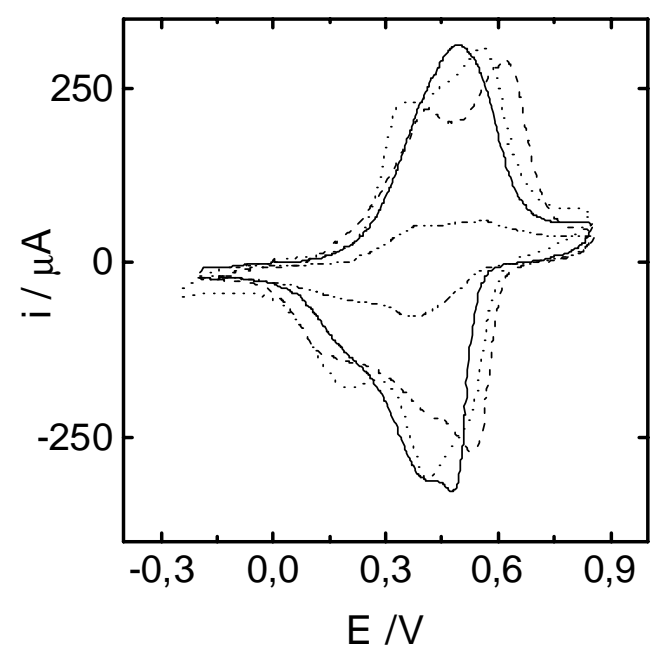

Figure 1. Cyclic Voltammograms of poly(2-ethylaniline) films cycled in $0.8 \mathrm{~mol} \mathrm{~L}^{-1}$ ( _ _ _ ) HCl, (- . - ) $\mathrm{HClO}_{4},(\ldots \ldots \ldots)$ PTSA and $(-. .-.$.$) HCSA electrolytic solutions. Sweep rate 0.01 \mathrm{Vs}^{-1}$. Polymerization conditions: $1 \mathrm{~mol} \mathrm{~L}^{-1} \mathrm{HCl}+0.5 \mathrm{~mol} \mathrm{~L}^{-1}$ 2-ethyl aniline. Experimental details as described in the text.

Differential scanning calorimetry experiments were performed with a Du Pont- TA Instruments- DSC 2010 equipment under $\mathrm{N}_{2}$ stream at a heating rate of $20^{\circ} \mathrm{C} \mathrm{min}^{-1}$. Scanning electron microscopy (SEM) micrographs were obtained with a Carl Zeiss, Model DSM 940A electron microscope with $4 \mathrm{~nm}$ of resolution. X-Ray diffraction measurements were made with a Rigaku Rotaflex (Model RU 200B) diffractometer using $\mathrm{Cu}-\mathrm{K}$ target.

\section{Results and Discussion}

Figure 1 shows i/E profiles of poly(2-ethyl aniline) films electropolymerized in $\mathrm{HCl}$ solutions and cycled in differ- 
ent acid electrolytes, $\mathrm{HCl}, \mathrm{HClO}_{4}$, PTSA and HCSA. It can be seen that the voltammetric response depends strongly on the counterion used. In the case of a small anion like $\mathrm{Cl}^{-}$ , the voltammogram presents only one large peak, while in the presence of other counterions such as $\mathrm{ClO}_{4}^{-}$, $\mathrm{PTS}^{-}$or $\mathrm{CSA}^{-}$, the splitting in two electrochemical processes can be distinguished. It also has to be pointed out in the case of the biggest anion $\left(\mathrm{CSA}^{-}\right)$that a very low current density is observed in comparison with the others counterions. This is an evidence of the great steric hindrance of the ethyl substituent to the insertion of a big anion into the polymeric matrix. When the polymer is prepared in HCSA solutions, the structure obtained is different from that observed for $\mathrm{PANI} / \mathrm{Cl}^{-}$films leading to higher current densities when the polymer is cycled in HCSA solutions. Figure 2 shows the i/ E profiles of two PANI films equivalent in charge formed in $\mathrm{HCl}$ and $\mathrm{HCSA}$ electrolytes cycled in camphor sulfonic acid solution. This fact shows the relevant role played by the counterion used in the synthesis of the polymer to determine its structure and, consequently, its properties. Redox potentials of electrochemical processes in poly(2-ethyl aniline) films are shifted from those corresponding to unsubtituted polyaniline films and, as it was shown in Figure 1, they depend on the charge/size ratio of the counterions. It is well-known that the electronic properties of aromatic polymeric systems are affected by changes in the torsion angle (dihedral angle) between adjacent rings of the polymer chain. The introduction of $\mathrm{C}_{2} \mathrm{H}_{5^{-}}$group on each phenyl ring increases the torsion angle and, consequently, decreases the degree of orbital overlapping between the $\pi$ electrons of phenyl rings with the nitrogen electron lone pair ( $\mathrm{sp}^{3}$ hybridization). This fact diminishes the extention of conjugation and increases the energy of the first oxidation process because it is more difficult to oxidize the completely reduced form of polyaniline (amine form). At this point, it is important to pay attention to two effects, eletronic and steric, that alkyl substituents produce in the polymer oxidation processes. The electron - donating nature of the ethyl group (Hammet constant $\sigma_{\mathrm{I}}=-0.05{ }^{13}$ ) indicates the shift of the first oxidation peak to less positive potentials than those observed in PANI. Experimental results (Figure 1) show that steric effects due to the increase of the dihedral angle, are stronger than the electronic ones leading to the polarization of the first oxidation peak of the 2-ethyl polyaniline film. Results are consistent with conductivity measurements of PANI and alkyl substituted polyaniline in which it was observed that the conductivity diminishes from PANI to poly(2-ethyl aniline) (Table 1). Electronic effects of the alkyl substituent are more important in the second redox process because once the radical cation is formed, its oxidation to the imine form must be facilitated by the presence of the $\mathrm{sp}^{2}$ hybridized nitrogens, which diminishes the steric strain due to wide dihedral angles and leads to a lower oxidation potential for the emeraldine/pernigraniline couple.

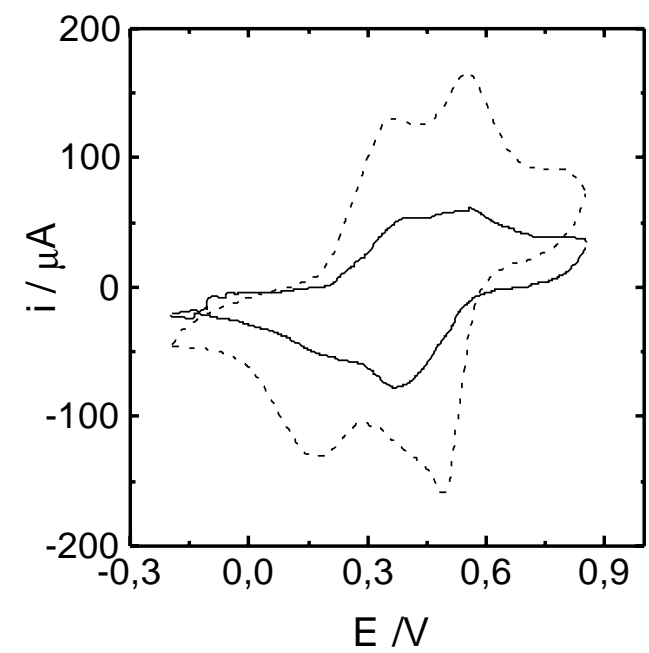

Figure 2. Cyclic voltammograms profiles of poly(2-ethyl aniline) films cycled in $0.8 \mathrm{~mol} \mathrm{~L}-1$ HCSA electrolytic solution. Sweep rate $0.01 \mathrm{Vs}^{-1}$. Polymerization conditions: (_ $) 1 \mathrm{~mol} \mathrm{~L}^{-1} \mathrm{HCl}+0.5 \mathrm{~mol} \mathrm{~L}^{-1} 2$ -

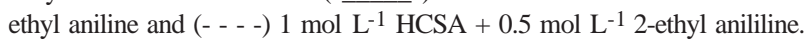

Table 1. Condutivities of chemicaly synthesized polyanilines and poly (2-ethyl aniline)

\begin{tabular}{ccc}
\hline Polymer & $\sigma\left(\mathrm{Scm}^{-1}\right)$, salt & $\sigma\left(\mathrm{Scm}^{-1}\right)$, base \\
\hline Polyaniline & $400-100 *, 5.6,0.7^{14}$ & $<10^{-10} \#$ \\
Poly(2-ethylaniline $)$ & $1.0 \times 10^{-3} \#$ & $<10^{-10} \#$ \\
\hline
\end{tabular}

* Secondary doping with CSA and $m$-cresol.

\# This work.

As mentioned above, substituted polyanilines present a strong electrochromism independently of the dopant used. In the specific case of poly(2-ethylaniline) films, they change from transparent yellow to blue with the potential ${ }^{10}$. Both electrochromism and electroactivity are related to the injection/ejection of charge carriers into/from the polymeric matrix. On this basis, we can associate the absorbance (A) with the inserted charge per unit area, as it was already done for inorganic and organic materials ${ }^{11,12}$ :

$\mathrm{A}=\varepsilon b c$

$\frac{\mathrm{dA}}{\mathrm{dt}}=\varepsilon b\left(\frac{\mathrm{dc}}{\mathrm{dt}}\right)=\frac{\mathrm{j} \varepsilon}{\mathrm{zF}}$

where $\varepsilon$ is the molar absorptivity of the film, $b$ is the film thickness, $c$ is the concentration of optically active sites on the electrode, $j$ is the current density, $z$ is the number of electrons participating in the redox reaction and $F$ is Faraday constant. 
If the reaction responsible for the coloration change of the material is the same producing a redox wave during the voltammetry and all the current consumed in the electrochromic reaction, the $\mathrm{dA} / \mathrm{dt} v s$ E profile must coincide with the i/E profile obtained under the same experimental conditions. This statement is correct if all current related to the electrochromic process has a faradaic nature and there is not a linear relationship between $\mathrm{dA} / \mathrm{dt}$ and capacitive current. In the specific case of poly(2-ethylaniline), it was observed that redox processes are not always separated by potential appearing as a large wave in the voltammogram; so that this approach can be specially useful to separate the redox reaction.

Figures 3 and 4 show the voltammograms together with the $\mathrm{dA} / \mathrm{dt}$ profiles recorded at different wavelengths for $\mathrm{HCl}$ and $\mathrm{HClO}_{4}$ electrolytes. As it can be seen, the first redox process, at less positive potentials, is associated with chromophore groups absorbing at $c a .420$ and $700 \mathrm{~nm}$; while the second process can be associated with groups absorbing at intermediate wavelengths. It is interesting to point out that $\mathrm{dA} / \mathrm{dt}$ profiles obtained at $620 \mathrm{~nm}$ do not separate both redox processes; that is to say that more than one chromophore is absorbing in this spectral region.

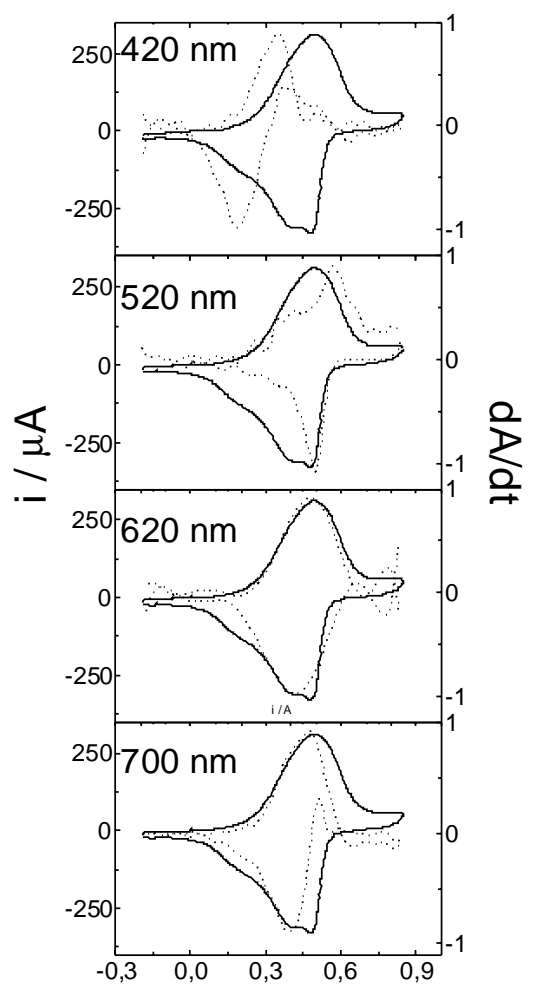

\section{E /}

Figure 3. i/E ( ___ $)$ and (-........) dA/dt vs.E potentiodynamic profiles of poly(2-ethyl aniline) films in $0.8 \mathrm{~mol} \mathrm{~L}^{-1} \mathrm{HCl}$ electrolytic solution, at different wavelengths. Sweep rate $0.01 \mathrm{Vs}^{-1}$.

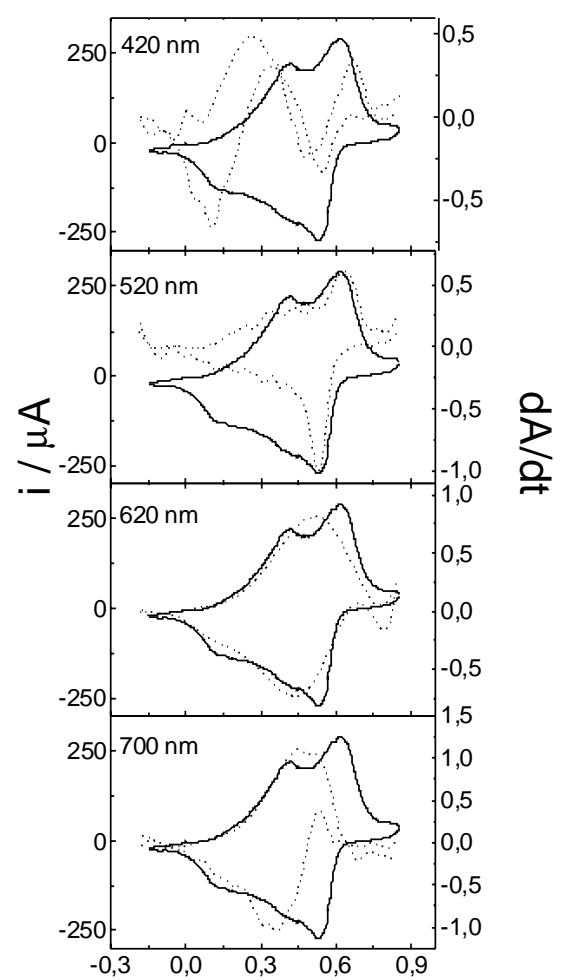

\section{E N}

Figure 4. i/E ( _ _ $)$ and (-........) dA/dt vs.E potentiodynamic profiles of poly(2-ethyl aniline) films in $0.8 \mathrm{~mol} \mathrm{~L}^{-1} \mathrm{HClO}_{4}$ electrolytic solution, at different wavelengths. Sweep rate $0.01 \mathrm{Vs}^{-1}$.

As it was shown in Figure 1, the voltammetric profile strongly depends on the dopant; consequently, electronic and optical properties of the polymer also change. That is why this analysis was performed for all the electrolytes and for polymers prepared by different methods. Changes in transmittance are proportional to the current observed in the voltammograms, in the sense that absorption in the case of big anions such as PTSA and CSA are smaller than those observed for $\mathrm{Cl}^{-}$and $\mathrm{ClO}_{4}{ }^{-}$.

\section{Morphological study}

Figures 5-8 show the microphotographs of $\mathrm{HCl}$ doped polyaniline film (Figure 5) and poly (2-ethylaniline) doped with $\mathrm{HCl}$ (Figure 6), $\mathrm{HClO}_{4}$ (Figure 7) and PTSA (Figure 8), respectively. As it can be observed, PANI films cycled in $\mathrm{HCl}$ appear as a very compact and homogeneous film in contrast with that observed in Figures 6 and 7, which can corroborate the spongeous structure of poly(2-ethyl aniline) cycled in mineral acids such as $\mathrm{HCl}$ and $\mathrm{HClO}_{4}$. This characteristic being more pronounced in the case of the biggest anion $\mathrm{ClO}_{4}^{-}$(Figure 7). Regarding Figure 8, the morphological aspect of poly(2-ethylaniline) cycled in PTSA is 
similar to that presented by the PANI film (Figure 5) confirming that the participation of PTS $^{-}$anions in the redox processes is minimum due to steric effects hindering the insertion of anions due to its size. This could be an indication, that in this case, the charge neutralization of the polymer is performed mainly by the expulsion of protons. Quartz crystal microbalance experiments will give more information about these phenomena.

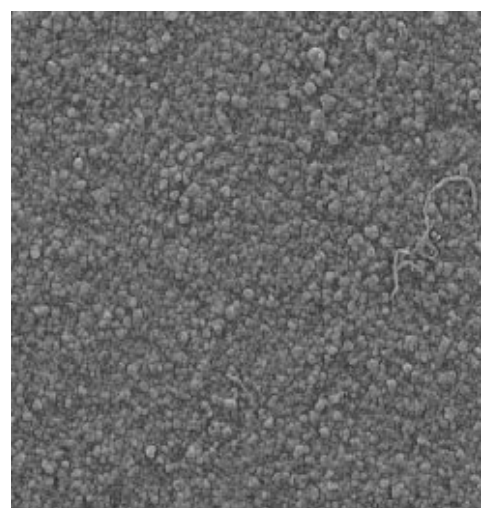

Figure 5. SEM micrograph of a Cl-/PANI doped film. The bar corresponds to $5 \mathrm{~mm}$.

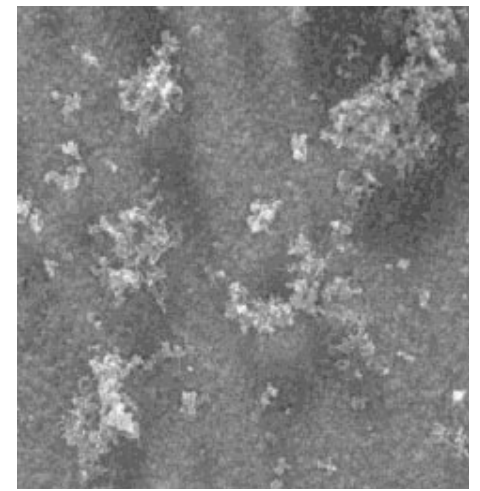

Figure 6. SEM micrograph of a $\mathrm{Cl}^{-} /$poly(2-ethyl aniline) doped film. The bar corresponds to $5 \mathrm{~mm}$.

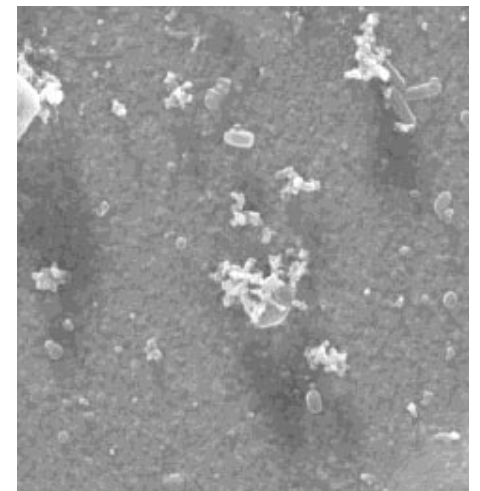

Figure 7. SEM micrograph of a $\mathrm{ClO}_{4}^{-/}$poly(2-ethyl aniline) doped film. The bar corresponds to $5 \mathrm{~mm}$.

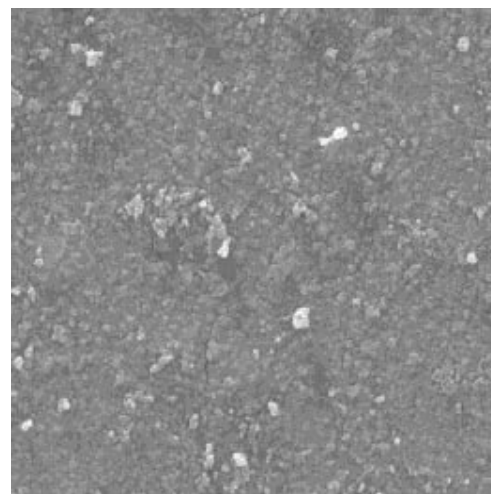

Figure 8. SEM micrograph of a PTS// poly(2-ethyl aniline) doped film. The bar corresponds to $5 \mathrm{~mm}$.

\section{Thermal study}

The causes of thermal deterioration of either doped or undoped polyanilines are still unclear; but the study of thermal stability of theses polymers is very important for film formation and processability. Figure 9 shows DSC curves for $\mathrm{PANI} / \mathrm{Cl}^{-}$and poly(2-ethyl anilne) $/ \mathrm{Cl}^{-}$powders. PANI trace indicates an endothermic transition centered at ca. $110^{\circ} \mathrm{C}$. This endotherm can be related to the evaporation of the water trapped inside the polymer or bonded to the polymer backbone. This endothermic process is almost not observed for poly(2-ethylaniline). This result can be attributed to the hydrophobic character of the ethyl substituents in the benzene rings. Two exotherms are observed in the DSC curves of both polymers; the temperature of this exothermic process being lower for poly(2ethylaniline). These processes are not believed to be a glass transition because, after cooling the polymer and running a second DSC, no exotherm transition is observed upon re-heating. In conclusion, these transitions must be related to a chemical irreversible reaction such as crosslinking which involves bond cleavage followed by a new chemical bond formation. Bond scissioning is normally an endothermic process while bond formation is an exothermic one, the overall reaction being an exothermic process. The presence of the two exotherms in both polymers could be due to different chains length. It can be concluded, that substituted polyaniline forms crosslinked structures at lower temperatures than the PANI polymer.

\section{Structural study}

Figure 10 shows the X-rays diffractograms of both chloride doped PANI (a) and 2-ethyl PANI (b) films obtained onto $\mathrm{SnO}_{2}$ substrates. As it can be seen, both polymers present large X-rays peaks indicating that the materials are rather amorphous with a certain degree of crystallinity. It can be inferred from the X-rays patterns that PANI films 
present a higher degree of crystallinity than the substituted polymer. These diffractograms are similar to those obtained by Pouget et al. ${ }^{15,16}$ for PANI and ring substituted polyanilines. Those authors have performed an exhaustive analysis of the X-rays patterns of polyaniline family and they concluded that bulky substituint groups lead to an increased disorder due to defects in stacking of the polymeric chains. The decrease of conductivity (Table 1) of the substituted material compared with PANI salt could be attributed to these structural modifications.

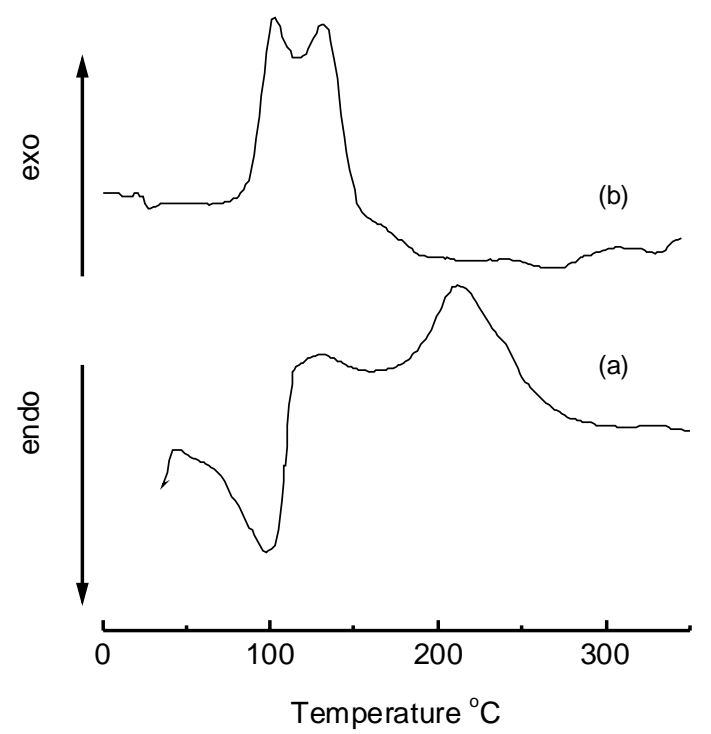

Figure 9. DSC curves of (a) polyaniline (b) poly(2-ethyl aniline) powders doped with chloride.
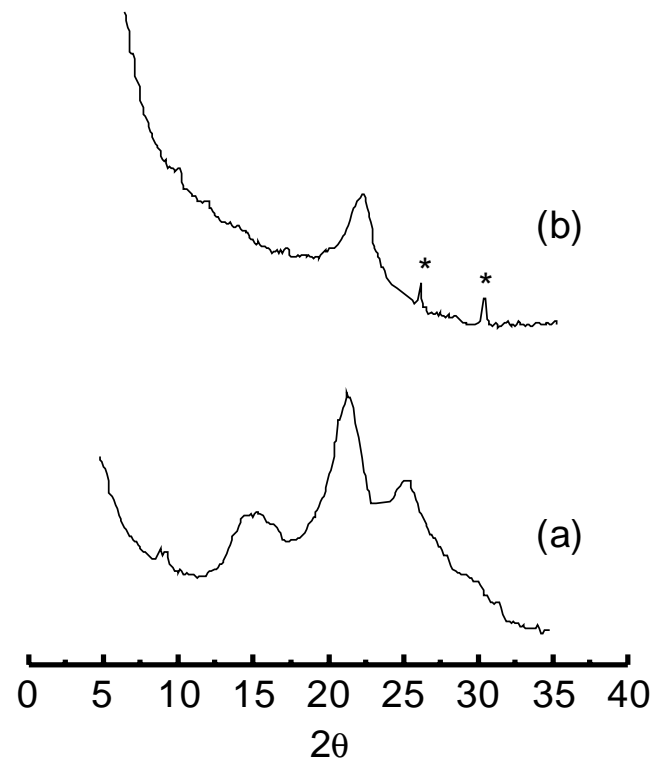

Figure 10. X-Rays patterns of (a) polyanline and (b) poly(2ethylaniline) films electropolymerized onto $\mathrm{SnO}_{2}$ substrates. Polymerization conditions: $1 \mathrm{~mol} \mathrm{~L}^{-1} \mathrm{HCl}+0.5 \mathrm{~mol} \mathrm{~L}^{-1}$ 2-ethyl aniline. *Diffraction peaks corresponding to $\mathrm{SnO}_{2}$ substrate.

\section{Conclusions}

A detailed comparative study of polyaniline and poly(2ethyl aniline) was presented. Spectroelectrochemical data show that, depending on the size of the counterion, the presence of an alkyl group in the ortho position will influence the participation of this anion in the ionic exchange process due to steric hindrance. The electron-donating effect of the ethyl substituent is completely disregarded as compared with the steric effect that produces an increase of the torsion angle between phenyl rings. The electronic effect is important in the second oxidation process and it is evidenced by the diminution of the redox potential of the emeraldine/pernigraniline couple. Differential absorbance curves when compared with the voltammograms, allowed to determine the wavelengths of the species formed of the poly(2-ethyl aniline). This approach has also allowed to distinguish the redox contributions in the case of complicated electrochemical responses.

Physical characterization from DSC experiments has shown the formation of crosslinked structures in both polymers which were characterized as an exothermic process occurring at lower temperatures for the substituted PANI. X-rays patterns of both PANI and 2-ethyl PANI films show a greater degree of disorder in the substituted material and defects in stacking of the polymer chains in the presence of the bulky ethyl group.

\section{Acknowledgements}

Authors are indebted to Brazilian agencies FAPESP (Proc. $N^{\circ}$ 98/14944-9 and 98/07264-8), CNPq, CAPES and the program PIBIC/CNPq. Drs. S.L. Cuffini (IFSC-USP and INFIQC, Argentina) andY. Kawano (IQ-USP) are gratefully acknowledged for providing X-Rays and DSC facilities, respectively. Authors also thank Mr. M. A. M.L. Prieto (DEMA-UFSCar) for technical support in SEM experiments.

\section{References}

1. Skothein, T. J. In Handbook of Conducting Polymers; Dekker, M., Ed.; New York, 1986; Vols. 1 and 2.

2. Anderson, M. R.; Mattes, B. R.; Reiss, H.; Kaner, R. B. Science 1991, 252, 1412.

3. Liang, W. B.; Martin, C. R. Chem. Mater. 1991, 3, 390 .

4. Gustafsson, G.; Cao, Y.; Traecy, G.M.; Klavetter, F.; Colaneri, N.; Heeger, J. Nature 1992, 357, 477.

5. Grem, G.; Leditzky, G.; Ullrich, B.; Leising, G. Adv. Mater. 1992, 4, 36.

6. Barlett, P. N.; Birkin, P. R. Synth. Met. 1993, $61,15$. 
7. Conklin, J. A.; Huang, S. C.; Huang, S. M.; Wen, T. W.; Kaner, R. B. Macromolecules, 1995, 28, 6522.

8. Skotheim, T. A. In Electroresponsive Molecular and Polymeric Systems; Dekker, M., Ed.; New York, 1991, Vol 1, p.106.

9. Kaufman, F. B.; Schoeder, A. H.; Engler, E. M.; Kramer, S. R.; Chambers, J. Q. J. Am. Chem. Soc. 1980, 102, 483.

10. Córdoba de Torresi, S. I.; Bassetto, A. N.; Trasferetti, B. C. J. Solid State Electrochem. 1998, 2, 24.

11. Córdoba de Torresi, S. I. Electrochim. Acta 1995, 40, 1101.

12. Gazotti Jr., W. A.; Jannini, M. J. D. M.; Córdoba de
Torresi, S. I.; De Paoli, M. -A. J. Electroanal. Chem. 1997, 440, 193.

13. Hine, J. In Structural Effects on Equilibria Organic Chemistry; Wiley; New York, 1975.

14. Wei,Y.; Focke, W.W.;Wneck, G. E.; Ray, A.; MacDiarmid, A. G. J. Phys. Chem. 1989, 93, 495.

15. Pouget, J. P.; Laridjani, M.; Jozefowicz, M. E.; Epstein, A. J.; Scherr, E. M.; MacDiarmid, A. G. Synth. Met. 1992, 51, 95.

16. Pouget, J. P.; Józefowicz, M. E.; Epstein, A. J.; Tang, X.; MacDiarmid, A. G. Macromolecules 1991, 24, 779 .

Received: June 15, 1999.

FAPESP helped in meeting the publication costs of this article. 